\title{
Pityriasis Alba: A Condition with Possibly Multiple Etiologies
}

\author{
Craig G. Burkhart ${ }^{*}, 1$ and Craig N. Burkhart ${ }^{2}$ \\ ${ }^{1}$ University of Toledo College of Medicine, USA \\ ${ }^{2}$ University of North Carolina at Chapel Hill, Chapel Hill, North Carolina, USA
}

\begin{abstract}
Pityriasis alba is a common hypomelanosis which is generally seen in young children. There is no specific known cause for this condition; however, studies to elucidate pathogenic factors seem to suggest that there are at least five separate causes for the condition. This list includes dermatitis, photosensitivity, fungal and bacterial pathogenesis, and post-inflammatory alterations. An evaluation into causative factors translates into alternative therapeutic options, which may be advantageous with affected individuals.
\end{abstract}

When a disease has diverse clinical presentations and no known cause, it is possible that one is looking at slightly different diseases with similar clinical characteristics.

Pityriasis alba is a common condition in practice mostly occurring in children between the ages of 3 and 16 , but can be additionally seen in young adults. It usually appears as dry, fine scaled, pale patches, 0.5 to $6 \mathrm{~cm}$ in diameter; however, often the flakiness is not present. The rash is limited to the face in $50 \%$ of cases, particularly the mid-forehead, malar ridges, and around the eyes and mouth; nevertheless, involvement of the shoulders, neck, back, and upper chest may predominate in others. It is symmetrical in distribution, but sometimes only marginally. The condition often begins as a pale pink or light brown macule with very indistinct margins, but it often just appears suddenly with decreased pigmentation. Macules vary from 5 to $30 \mathrm{~mm}$ or larger.

The condition is so named as 'pityriasis' means scaly and 'alba' is the word for white in Latin. Of note, the patches in pityriasis alba are not totally depigmented as with vitiligo. The hypopigmentation with pityriasis alba is due to both reduced activity of melanocytes as well as fewer and smaller melanosomes; in vitiligo, on the other hand, there is total loss of both melanocytes and melanosomes. Histologically, the condition reveals subacute spongiotic dermatitis with decreased melanin within the epidermis. A differential diagnosis would include vitiligo, psoriatic leukoderma, tinea versicolor, follicular mucinosis, pityriasis lichenoides chronica, sarcoidosis, adult T-cell leukemia/lymphoma, and mycosis fungoides.

There is no specific known cause for this condition; however, studies to elucidate pathogenic factors seem to suggest that there are at least five separate causes for the condition. First, there is an increased incidence in individuals who bath excessively, defined as showering over once daily [1]. This could infer that removal of normal epidermal defensins and other natural protective substances from the skin surface,

*Address correspondence to this author at the University of Toledo School of Medicine, 5600 Monroe Street, Suite 106B, Sylvania, OH 43560, USA; Tel: 419-885-3403; Fax: 419-885-3401; E-mail: cgbakb@aol.com makes one more prone to this condition. Certainly, any inflammation of the skin may affect pigment cell function. Indeed, many consider the disease to be a mild form of eczema.

Secondly, photosensitivity may also play a role in this entity [1]. The peak incidence of the condition coincides with the age when children begin to do more outdoor activities. Typical location of lesions is in sun-exposed areas. Also prolonged sun exposure of several hours also increases one's chances of developing the condition. Thus, the melanocytes appear to be sensitive to sun in these patients.

Hypopigmentation can also be explained by damage to melanocytes and inhibition of tyrosinase by decarboxylic acid, azelic acid (a competitive inhibitor of tyrosinase), and/or tryptophan-derived metabolites produced by normal yeast, namely Malassezia furfur, a yeast that is part of the skin surface's normal flora $[2,3]$. Thus, some pityriasis alba patients have a sensitivity to the byproducts of this fungus. Unlike tinea versicolor, the organism is not increased in numbers in pityriasis alba. Also, pathogenic fungus are not involved with this condition [4].

Propionibacterium acnes bacteria, which live in the hair follicles, has been considered as a possible producer of a hypothetical depigmenting factor [5,6]. Pityriasis alba is frequently noted in children with early comedonal and popular acne. Propionibacterium acnes was yielded from cultured biopsy specimens taken from follicular lesional skin [6]. Propionibacterium acnes produces a number of bioactive virulence factors and is known for its inflammatory and immunomodulatory properties $[7,8]$. A number of exocellular enzymes and metabolites can directly damage host tissue including melanocytes [9].

Additionally, pityriasis alba may be merely secondary to postinflammatory changes. Indeed, studies of alterations of the stratum corneum by both hygroscopicity and waterholding capacity detectable by water sorption-desorption testing support this theory [10].

An evaluation into causative factors translates into alternative therapeutic options, which is advantageous with conditions which lack a definitive cure. Evaluations of causes of pityriasis alba are therefore warranted. 


\section{REFERENCES}

[1] Weber MB, de Avila LGS, Albaneze R, de Oliveira OLM, Sudhaus $\mathrm{BD}$, Cestari TF. Pityriasis alba: a study of pathogenic factors. JEADV 2002; 16: 463-8.

[2] Thoma W, Kramer HJ, Maysert P. Pityriasis versicolor alba. JEADV 2005; 19: 147-52.

[3] Aljabre SHM, Alzayir AAAA, Abdulghani M, Osman OO. Pigmentary changes of tinea versicolor in dark-skinned patients. Int $\mathrm{J}$ Dermatol 2001; 40: 273-5.

[4] Vinod S, Singh G, Dash K, Grover S. Clinico-epidemiological study of pityriasis alba. Ind J Dermatol 2002; 68: 338-40.

[5] Relyveld GN, Menke HE, Westerhof W. Progressive macular hypomelanosis. Am J Clin Dermatol 2007; 8: 13-9.
[6] Westerhof W, Relyveld GN, Kingswijk MM, de Man P, Menke HE. Propionibacterium acnes and the pathogenesis of progressive macular hypomelanosis. Arch Dermatol 2004; 140: 210-4.

[7] Perry AL, Lambert PA. Propionibacterium acnes. Lett App Microbiol 2006; 42: 185-8.

[8] Burkhart CG, Cantrill J, Butcher CL, Lehmann PF. Propionibacterium acnes: interaction with complement and development of an enzyme-linked immunoassay for the detection of antibody. Int $\mathrm{J}$ Dermatol 1999; 38: 200-3

[9] Allaker RP, Greenman J, Osborne RH. The production of inflammatory compounds by Propionibacterium acnes and other skin organisms. Br J Dermatol 1987; 117: 175-83.

[10] Urano-Suehisa G, Tagami H. Functional and morphological analysis of the horny layer of pityriasis alba. Acta Dermato-Vener 1985; 65: 164-7.

(C) Burkhart and Burkhart Licensee Bentham Open.

This is an open access article licensed under the terms of the Creative Commons Attribution Non-Commercial License (http://creativecommons.org/licenses/by$\mathrm{nc} / 3.0 /$ ) which permits unrestricted, non-commercial use, distribution and reproduction in any medium, provided the work is properly cited. 